\title{
Typhoid Fever in an Ethiopian Health Center
}

\author{
Bikila Wedajo Lemi \\ Department of Biology, College of Natural Sciences, Arba Minch University, Arba Minch, P.O. Box 21, Ethiopia
}

\begin{abstract}
Objectives: Typhoid fever due to Salmonella enterica serovars Typhi and Paratyphi occur in urban areas with poor sanitation. So, the objective of this study was to assess the trends and prevalence of typhoid fever at Arba Minch Health Center in the past five years, $2014-2018$ by using the medical records of patients.

Methods: A retrospective study was performed in Arba Minch Health Center between 2014 and 2018. All data of the patients which were suspected for typhoid fever were collected from log patients log books.

Results: In total 1,765 patients' records were followed with typhoid fever diagnosis. The findings of the study revealed that typhoid fever decreased from the year 2014 to 2018 and the incidence of the disease was high at the ages between 5 and 15, but varied, especially in the ages between 16 and 30 years. The overall sex differences in this study were $836(47.4 \%)$ males and 923 (52.3\%) were female. This indicates, females were more susceptible to this disease compared to their counterparts, males.
\end{abstract}

Conclusions: Based on the major findings, it has been important to regularly promote the awareness of the people on the causes of the disease, its method of infection, its mode of transmission and its control method. $J$ Microbiol Infect Dis 2019; 9(3):150-154.

Keywords: Epidemiology, Pathogenesis, Widal test, Typhoid fever

\section{INTRODUCTION}

Typhoid fever caused by Salmonella enterica serovars Typhi remains a major health problem globally. It affects about 21.7 million people, with 217,000 deaths occurring worldwide on an annual basis [1]. It is common in developing countries where it affects 12.5 million people each year. For instance, over 42,000 cases and 1,214 deaths were recorded in Congo between 2004 and 2005. Cases are more likely to be seen in areas like India, South and Central America, and Africa with rapid population growth, increased urbanization, and limited safe water, infrastructure, and health systems [2-4]. Although national surveillance studies are lacking in Ethiopia, the individual study reported $4.1 \%$, prevalence of typhoid fever among patients with febrile illnesses. Moreover, a systematic and meta-analysis study in Ethiopia showed typhoidal Salmonella (S. typhi) accounted for $42.1 \%$ of the total isolates of Salmonella species reported from 1974 to 2006 years indicating typhoid fever is endemic in Ethiopia [5-11].
Typhoid fever is a major public health problem in low-income and middle-income countries like Ethiopia where there are substandard hygiene and unsafe drinking water supplies and the quality of life is poor [6-10]. Epidemiologic data on typhoid fever in endemic countries is lacking or incomplete [5]. In Ethiopia, several factors including under and malnutrition, HIV-AIDS, the unhygienic living circumstances and the close relations between humans and animals may substantially contribute to the occurrence of Salmonellosis [11]. Transmission of the bacterium is mainly through ingestion of fecaloral route through contaminated food and water and consuming raw milk products, flavored drinks and ice creams $[2,7,9]$. It is a severe systemic illness characterized by fever and abdominal pain and has the ability to survive for several months in soil and water [3].

There is no doubt as to the endemicity of Typhoid fever in Ethiopia, but precise estimate of prevalence of typhoid fever among patient is unavailable and there is no coordinated epidemiological surveillance $[12,13]$. Similarly,

Correspondence: Bikila Wedajo Lemi, Department of Biology, College of Natural Sciences, Arba Minch University, Arba Minch, Ethiopia. 
there was very little information on the epidemiology of typhoid fever in the current study area. Therefore, the present study was designed to assess typhoid fever among patients treated in Arba Minch Town health center based on the hypothesis that there is a trend of typhoid fever among patients treated in Arba Minch Health Center between 2014 and 2018.

\section{METHODS}

\section{Description of the Study Area}

Arba Minch, which is the administrative center of Gamo Zone is located in the Southern Nation, Nationality and Peoples Region (SNNPR) in the Federal Republic of Ethiopia. It is $\mathbf{5 0 5}$ kilometers away from Addis Ababa, the capital city of Ethiopia. The global position of Arba Minch is located at latitude $6^{\circ} 4^{\prime} \mathrm{N}$ and longitude $36^{\circ} 27^{\prime} \mathrm{E}$. The specific site lies at an elevation of 1,235 meters above sea level. The mean annual rainfall characterized by a bimodal type is 521$2105 \mathrm{~mm}$ including 2 wet seasons (first from the end of March to mid-June, second from midSeptember to late November) and 2 dry seasons (first from December to mid-March, second from the end of June to mid-September) [14]. The mean annual temperature varies between 14.5 ${ }^{0} \mathrm{C}$ (September to November and April to June) and $33.2{ }^{\circ} \mathrm{C}$ (February and March). Hence, from the combined effect of altitude, temperature and rainfall, one can conclude that the town is classified as dry upper kola eco-climate zone. The area is commonly characterized with poor sanitation of water that can be used for personal hygiene and drinking purpose which increases the chance to be caught by typhoid fever (Figure 1).

\section{Study Setting}

To assess typhoid fever, Arba Minch Health Center where many patients from the Arba Minch town and vicinity were diagnosed and treated was selected for the current research. The author used one Health Center, which is known as Arba Minch Health Center for this study. The center is one of the known diagnostic and treatment center for typhoid fever in the study area (Arba Minch Town).

\section{Study Design}

A retrospective study using secondary data was done to assess typhoid fever disease among patients diagnosed and treated in Arba Minch Health Center (AHC) from 2014-2018.

\section{Study Population}

Patients visiting Arba Minch Health Center during the study period were the population for the study. Data from the hospital for the period from January 2014 to August 2018 indicated that out of the total patients attending the health center, 1765 febrile cases were diagnosed as enteric fever.

\section{Methods of Data Collection}

A secondary data were collected by using the prepared check list like individuals with different age groups and sex from log books of clients of patients treated in Arba Minch Health Center between 2014 and 2018.

\section{Laboratory examination}

The Widal slide agglutination test was done using $\mathrm{S}$. Typhi $\mathrm{O}$ and $\mathrm{H}$ antigens according to the instructions of the manufacturer. The antigen suspension commercially available in $5 \mathrm{ml}$ volume from SPINREACT Reagent Ltd. (Spain) was used. A direct slide agglutination technique was used in this study for qualitative determination of the agglutination ability of sera. In brief, the test was done by mixing one drop of serum with one drop each of $\mathrm{O}$ and $\mathrm{H}$ antigens separately on slide. After shaking the slide back and forth for $1 \mathrm{~min}$, the mixture was observed for macroscopic agglutination. If there was agglutination within $1 \mathrm{~min}$ it was reported as reactive, otherwise, non- reactive.

\section{Data Analysis}

The SPSS package 2020 Version was used to analyze data.

\section{Ethical Considerations}

The study was approved by Arba Minch University, College of Natural Sciences, and Department of Biology. An ethical letter was taken from the department and provided to the medical director. After it was approved by the medical director, the letter was provided to the medical statistics officer and the collection of data was done. 


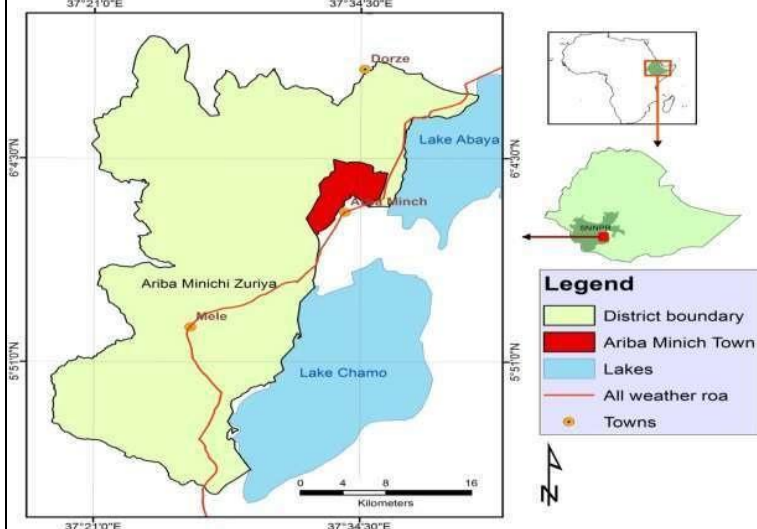

Figure 1. Map of description of the study area (Arba Minch Town) is the place where the Health Center was found.

\section{RESULTS}

In total 1,765 individuals were diagnosed as typhoid fever in the past five years. The distribution of typhoid fever varied in years by years. The highest number of cases was found as $660(37.39 \%)$ in 2014 . The highest number of cases was in 2015 and the lowest number in 2014. In each year, more females were affected than males. The overall sex differences in this study were $836(47.37 \%)$ males and 923 $(52.30 \%)$ were female (Table 1$)$.

Concerning the results on the total number of individuals infected with typhoid fever at different age groups between 2014 and 2018 was shown in the Figure 2. The highest number of cases was between 15 and 30 years and followed by the group between 5 and 15 years (Figure 2).

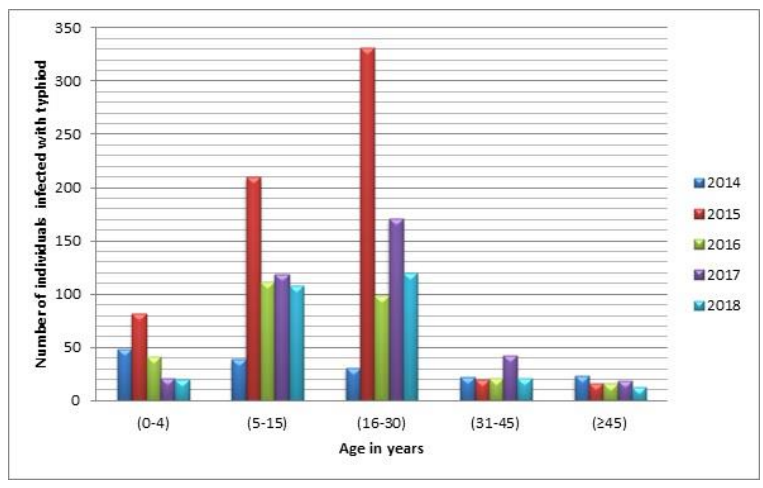

Figure 2. Age wise comparison of Widal test positivity of typhoid fever between 2014 and 2018.

\section{DISCUSSION}

To our knowledge, this is the first assessment of the study area that indicates typhoid data over a past five year period. The major objective of this study was to assess the trends of typhoid fever in Arba Minch health center for the last five years, 2014-2018. In order to achieve this purpose, specific objectives were raised in the study. Based on the analysis of the data, the researcher describes the reality of the case herein below categorizes, its age association, sex association, and seasonal distribution.

In all cases, females were more affected than males. This finding shows concordance with the previous studies. Some studies reported high prevalence among female than male $[16,17]$. Although studies reported that there is no significant difference in the occurrence of typhoid between urban and rural environments [19], in this study, since most of the patients are from rural residents' higher risk of typhoid fever as compared to urban residents. This could be explained by suboptimal access to safe water and lack of hygienic education which was supported by the high prevalence of typhoid among farmers with no formal education [19].

Table 1. Assessment of the disease among male and female in each year compared to the total number of patients between 2014 and 2018

\begin{tabular}{cccc}
\hline Year & Sex & No. of Patients $(\%)$ & $\begin{array}{c}\text { Total No. } \\
(\%)\end{array}$ \\
\hline 2014 & M & $76(4.31)$ & $163(9.24)$ \\
& F & $87(4.93)$ & $660(37.39)$ \\
2015 & M & $321(18.19)$ & \\
& F & $339(19.20)$ & $288(16.32)$ \\
2016 & M & $146(8.27)$ & $372(21.07)$ \\
& F & 1428.05 & $282(15.98)$ \\
\hline 2017 & M & $155(8.78)$ & \\
\hline 2018 & F & $217(12.29)$ & $1765(100)$ \\
\hline \multirow{2}{*}{ Total } & M & $138(7.82)$ & \\
& F & $144(8.16)$ & \\
\hline
\end{tabular}

$\mathrm{M}=$ Men, $\mathrm{F}=$ Female

Age wise children below 15 ages were mostly affected than the rest of age group. However, in 2015, 2017 and 2018 children below 15 ages were decreased, whereas between 16 and 30 increased and also decreased above 30 years, only in 2016 the most likely affected in between 
5 and 15 years then above 16 years the distribution of disease was decreased.

In each year the number of infected individuals varied in number in each year as age increased. In this study, the high odds of typhoid fever among the age group is perhaps as a result of lack of sufficient safe drinking water, toilet and water for hand washing after the toilet in their home. This probably creates a greater opportunity for person-to-person transmission in these congregated sites.

Though typhoid cases are observed throughout the year, the peak incidence of typhoid fever is reported during the summer in endemic areas. In recent years, most parts of the country have experienced the change in timing of the rainy season from year to year, the main rains season mid-March up to June and the second shifts to September - mid-December, which seems to match with the observed shift of high transmission time of typhoid fever from (20142018) but only in 2017 the most frequented patient was recorded in February this may due to seasonal fluctuation and other related disease might affect the society. The typhoid fever high transmission season normally takes place in the latter part of the rainy season, a period that coincides with the rainy season characterized by low river levels and a substantial increase in the fly population [18].

This study has some limitations in light of which results need to be interpreted. First, as a Health center-based study that enrolled participants in the outpatient department, typhoid patients that don't seek health care at the Arba Minch Health Center were missed. Second, identification of species by anti-sera and antibiotic susceptibility test for the isolated pathogen was not done. Third, access to safe water, toilet, environmental sanitation and occurrence of the outbreak was not assessed during the study period. Forth, the study was restricted to one health center due to lack of budget; so, relatively small sample size was used in the case.

As conclusion, our study showed that typhoid fever cases were between 15 and 30 years and beside children below the age 15 were most affected. The women were more likely affected than their counterparts, males.

\section{ACKNOWLEDGMENTS}

I appreciate the Medical Superintendent and Head of Department of Records for their permission for me to access the data bank. I appreciate my field assistants, for their various contributions towards the success of this study.

Declaration of Conflicting Interests: The authors declare that they have no conflict of interest.

Funding: Not declared.

\section{REFERENCES}

1. Crump JA, Mintz ED. Global trends in typhoid and paratyphoid fever. Clin Infect Dis 2010; 50:241246.

2. Marathe SA, Lahiri A, Negi VD, Chakravortty D. Typhoid fever \& vaccine development: a partially answered question. The Indian journal of medical research 2012; 135 (2):161.

3. Akubuenyi FC, Uttah EC, Enyi-Idoh $\mathrm{KH}$. Microbiological and physicochemical assessment of major sources of water for domestic uses in Calabar Metropolis Cross River state, Nigeria. Transnation J Scien Technol 2013; 3(2):31-44.

4. Willke A, Ergonul O, Bayar B. Widal test in diagnosis of typhoid fever in Turkey. Clin Diagn. Lab. Immunol 2002; 9(4): 938-941.

5. Abucejo PE, Capeding MR, Lupisan SP, et al. Blood culture confirmed typhoid fever in a provincial hospital in the Philippines. Southeast Asia J trop Med Publ Health 2001; 32(3):531-536.

6. Mogasale $\mathrm{V}$, Maskery $\mathrm{B}$, Ochiai RL, et al. burden of typhoid fever in low-income and middle-income countries: a systematic, literature-based update with risk-factor adjustment. Lancet Glob Health 2014; 2:e570-e580

7. Mama M, Alemu G. Prevalence, antimicrobial susceptibility patterns and associated risk factors of Shigella and Salmonella among food handlers in Arba Minch University, South Ethiopia. BMC Infect Dis 2016; 16:686.

8. Zeru K, Kumie A. Sanitary conditions of food establishments in Mekelle town, Tigray, north Ethiopia. Ethiop J Health Dev 2007; 21(1):3-11.

9. Farooqui A, Khan A, Kazmi SU. Investigation of a community outbreak of typhoid fever associated with drinking water. BMC Public Health 2009; $9: 476$.

10. Kanungo S, Dutta S, Sur D. Epidemiology of typhoid and paratyphoid fever in India. J Infect Dev Ctries 2008; 2(6):454-60.

11. Tadesse G. Prevalence of human Salmonellosis in Ethiopia: a systematic review and meta-analysis. BMC Infect Dis 2014; 14:88. 
12. Beyene G, Asrat D, Mengistu Y, Aseffa A, Wain J. Typhoid fever in Ethiopia. J Infect Dev Ctries 2008; 2(06):448-453.

13. Pang T. Typhoid fever research in developing countries. J Infect Dev Ctries 2008; 2(6): 411.

14. Assefa E, Bork HR. Dynamics and driving forces of agricultural landscapes in Southern Ethiopia-A case study of the Chencha and Arbaminch areas. J Land Use Scien 2016; 11(3):278-293.

15. Abera B, Biadegelgen F, Bezabih B. Prevalence of Salmonella typhi and intestinal parasites among food handlers in Bahir Dar Town, Northwest Ethiopia. Ethiop J Health Develop 2010; 24(1).

16. Modebe AA, Nnachi AU, Ukaegbu CO, et al. Dual infections of Enteric Salmonella species with Schistosoma mansoni among Patients from two Hospitals in Jos, Nigeria. J Appl Environ Microbiol 2014; 2(4):198-202.

17. Uttah EC, Osim SE, Etta H, Ogban E, Okon NE. Four-year longitudinal assessment of the prevalence of typhoid fever among those attending the General Hospital Etinan, Nigeria. Intern J Scien Resear Public 2013;3(7):150-153.

18. Luxemburger C, Duc CM, Lanh MN, et al. Risk factors for typhoid fever in the Mekong delta, southern Viet Nam: a case-control study. Trans Royal Soc Trop Med Hyg 2001; 95(1):19-23.

19. Dewan AM, Corner R, Hashizume M, Onge ET. Typhoid fever and its association with environmental factors in the Dhaka Metropolitan Area of Bangladesh: a spatial and time-series approach. PLoS Negl Trop Dis. 2013; 7(1):e1998. 